\title{
Impact on Military Children When a Parent Deploys While Living Overseas a Brief Scope of the Literature
}

\author{
George Hough* \\ RAF Lakenheath, UK
}

Submission: November 06, 2017; Published: December 01, 2017

*Corresponding author: George Hough, RAF Lakenheath, UK; Email: david.hough.5@us.af.mil

\begin{abstract}
This brief literature scope examines the impact upon military dependent children who experience a parent's deployment while living overseas. While much is known about the impact on these children when a parent deploys, there is no research that describes the impact upon them when these dependent children have moved with their families to an overseas assignment and then their parent subsequently deploys. Analog literature on child immigration was reviewed to help bridge this research gap. It is hypothesized that a parent's deployment while living overseas thereby creates a kind of unique "double-stressor" for these children that is typically diagnosed as a variation of adjustment disorder. Though many military dependent children do display significant psychological resilience when confronted with this situation, there are some who require short-term behavioral health services to help them re-balance. Treatment interventions for these children targets restoring the child's inner sense of connection with their absent parent and with their culture of origin. This paper contributes to the U.S. military's ongoing efforts to support the families of active duty service members while on deployment, and is an initial effort to better understand this doublestressor phenomenon.
\end{abstract}

Keywords: Military deployment; Acculturation; PCS; Resilience among military children; Children and immigration

Abbreviations: PCS: Permanent Change of Station; NMFA: National Military Family Association; DoD: Department of Defense; CONUS: Continental United States

\section{Introduction}

Much is known about the emotional responses that military dependent children may express while residing in the United States when one of their active duty parent's deploys to a new duty assignment either within or outside of the U.S. [1]. U.S. Department of Defense [2]. These deployments are of varying lengths of time, typically for a year or less. By contrast, practically nothing is known about the emotional responses of military children who have been living overseas and still settling into their new host country when their active duty parent deploys. By itself the PCS [Permanent Change of Station] relocation experience to an overseas facility for military children is predictably stressful but usually manageable. Yet when the adjustment to this foreign relocation is subsequently followed byan active duty parent's lengthy and sometimes sudden and unanticipated deployment away from the family, the departure of the parent in this context now constitutes a kind of doublestressor for the child. The cumulative impact of the PCS and the parent's deployment, as back-to-back stressors, can for some children temporarily overwhelm their ability to cope. For most of the children confronted with this particular kind of doublestressor, news of the parent's new deployment will typically feel at a minimum like an unanticipated shock. In some cases a referral for short-term for behavioral health intervention may be indicated.

There are multiple factors that can influence how resilient or vulnerable any particular child may be to this double-stressor; these factors, but to name a few, can include: how well the child has adjusted to the move to the new country before the parent's deployment; the timing and nature of the parent's new deployment [temporal duration, ease of communication with the family while deployed, high risk vs. low risk location]; the child's age and level of development, and the degree of psychosocial support available to the child and family while the parent is away. The range of adjustment styles these children may demonstrate, and the factors that will support or impede their success with any given adjustment style is, indeed, broad.

\section{Impact of Deployments on Military Children}

The corpus of research literature on the effects of deployment and its aftermath on the children of military service members has been growing steadily over the past several decades. Far more is known about the emotional impact of deployments upon 
military children when they are living in the United States with their family and while they still have their extended support system available to them. Though not all military deployments are to war zones, having a primary caretaker deployed to a warzone for an indeterminate period is among the more stressful events a child can experience (The Psychological Needs of U.S. Military Service Members and Their Families: A Preliminary Report, 2007). The Cycles of Deployment Survey, conducted by the National Military Family Association (NMFA), found that the notification of a pending deployment initiates a time of significant stress for family members (National Military Family Association, 2005). Repeated and extended separations and the increased hazards of deployment for the service member amplify these stressors for families and children. Many family members left behind during deployment experience a period of emotional destabilization and disorganization $[3,4]$. The range of specific emotional reactions reported include: sadness, depression, disorientation, anxiety, and loneliness, feeling overwhelmed, numbness, anger, and relief [5,6]. Physical reactions may also emerge, such as sleep and health problems [7,8]. Routine family responsibilities and household tasks can begin to feel overwhelming [9].

For a more comprehensive review in this area see the RAND Report, "How Deployments Affect Service Members" [10] which describes the deployment cycle process and the negative impact deployments can have on service members and families. It is noted, as well, that when the deployment ends the reunion phase with the family begins. Yet, as the National Military Family Association (NMFA, 2005) reported, rather than a cycle of deployment, there is a spiral: "Families never come back to the same place they started" (p. 14). The reunion phase heralds its own set of challenges and stressors [11] Posits that the reunion and post-deployment processes are little understood and more complex than previously believed, especially when the possibility of redeployment looms [12]. Significant gaps thus remain in our understanding of the complex psychological and social effects the Global War on Terror has had on military families when a family member deploys. [13] Highlighted future research directions in this area by summarizing the results of the 2011 CNA Workshop on the Scientific Study of Military Children. There is opportunity to expand this research by looking at theory and research findings as applied to civilian children and families. More recently the deployment literature has reflected an important area of emergent research that describes the concept of emotional resilience.

\section{Emotional Resilience}

Emotional Resilience (2) is a psychological coping term that is frequently discussed in the military deployment literature as it refers to both active duty service members as well as their dependents. A number of researchers have examined factors that promote resilience among military families, including family readiness, active coping, "making meaning", social support, acceptance of the military life style, optimism, self-reliance, and the ability to adapt flexibly to gender roles [14-17]. Observed that despite the numerous strains on the deployed families that most of them do display a remarkable degree of resilience that enables them to "rise to the occasion", and adapt successfully to the stress of having a family member deploy. In large- $\mathrm{N}$ epidemiological studies the overall levels of psychopathology in military children have also been found to be at or below those observed in the civilian population $[18,19]$. As noted by Fox, Henderson, Perez-Edgar and White [20], as well as Belsky and Pluess [21], toxic or stressful environments can be managed if children can find secure and supportive relationships with parents or other supportive individuals. Interventions that aim to ameliorate these difficulties can help children build resilience. Family readiness is considered a key factor in promoting and developing resilience, with family preparedness serving as a strong protective factor when confronted with deployments. Research on civilian children demonstrates that effective education, and being provided with opportunities to help others, helps to promote positive youth development and resilience $[22,23]$.

PCS (Permanent Change of Station) within the Continental United States (CONUS) and Military Children

We turn next to the emotional impact of the PCS [Permanent Change of Station] experience on military children within the U.S. According to the Department of Defense (DoD), the average military dependent will face PCS transition challenges more than twice during high school, and most military children will attend from six to nine different school systems in their lives from kindergarten to $12^{\text {th }}$ grade [24]. With the PCS within CONUS (Continental United States), it is generally agreed that geographic mobility (multiple moves) and isolation, frequent separations, and the normative constraints of the military culture can have a detrimental impact on children in military families [25-29]. While there is ample literature that documents the negative impact upon children with PCS transitions within the U.S., there is also a counterbalancing corpus of literature (as noted above with resilience literature) that describes these children's resilience and positive ability to cope, and the many positive benefits that can accrue for them from a PCS relocation. Children's responses to a PCS naturally vary depending upon the child's age and developmental stage, as well as other family and individual factors [30-32]. There is thus a mixed picture regarding the impact of a PCS within the United States for military dependent children. Some of these children will adjust to these moves better than others and there are multiple developmental and individualized factors that must be considered with each child.

\section{PCS and Military Children to Foreign Countries}

In contrast to the literature on the emotional impact upon military dependent children who PCS within the U.S., research that addresses the emotional impact upon dependent children 
who PCS to a foreign country is at present very sparse or essentially non-existent. Some of the above referenced studies of the emotional impact on children who PCS within the U.S. may have included within them some children who were moving overseas. However, as these studies typically do not clearly differentiate between these two populations, clear patterns in adjustment styles between those children who will PCS within the U.S. and those who will PCS overseas, cannot be neatly separated. We thus briefly turn to analogue studies from the literature on child immigration to partially bridge this gap in the research.

\section{Child Immigration}

For dependent military children their experience with PCS relocation to a foreign country has some tangential similarities (and dissimilarities) to the acculturation experience of immigrant children who immigrate to a new country to resettle. Immigration to the new culture can occur for many reasons, and these may be voluntary or involuntary [as in the case of war refugees]. There are several well recognized markers by which the child's cultural adaptation to the new country's culture can be measured. These would include: mastery of the new culture's language(s), becoming familiar with its ethnic diversity, and the degree to which the child participates in the new culture's activities (see APA Task Force on the Psychosocial Effects of War on Children and Families Who are Refugees from Armed Conflict Residing in the United States [33]. Notes that there are large group and individual differences in acculturation strategies, which are described in terms of four basic strategies for both adults and children: integration, assimilation, separation and marginalization strategies. The particular acculturation strategy child adapts will partially determine how much stress he or she may experience in the acculturation process, as well as how well they will adapt longitudinally to their new culture psychologically and socially. Acculturation stress occurs when problems of acculturation emerge for the child. On balance, those children who actively attempt to integrate into the new culture will experience less stress and achieve better levels of adaptation than those who pursue a marginalization strategy where contact with the new culture is avoided. Among siblings within families, acculturation often proceeds at different rates. This can sometimes lead to an increase in conflict and stress within the family and to making the process of cultural adaptation more difficult for the entire family [34].

At a deeper psychological level, a PCS to a foreign country can present a child with a confluence of sudden and disruptive psychological changes that depart radically from what they have otherwise taken for granted as inherent to their "average expectable environment" [35] such as when they previously lived at home in the United States. When these cultural changes are experienced as occurring too abruptly or too fast, then the child may experience what is commonly referred to as a variation of "culture shock" [36-38] as they confront their new environment.
Such jarring dislocations in the child's sense of time, as well as their grounding in space and geography, can create a disruption in the fabric of the child's internal life experience and sense of core identity. The pain inherent in this relocation process compels the child to confronta radically altered external and internal environment. A psychological mourning process is thereby initiated which requires the child to grieve their lost sense of self as they had once experienced it, and there by now ruptured attachment to a once stable and familiar cultural and physical world [39]. As described by Volkan [40] in the case of refugee children: since moving from one location to another involves loss- loss of country, loss of friends, and loss of previous identity- all dislocation experiences may be examined in terms of the immigrant's or the refugee's ability to mourn and/or resist the mourning process. The extent to which the individual is able to intra psychically accepts his or her loss will determine the degree to which an adjustment is made to the new life (p. 65).

Psychoanalyst Salman Akhtar, who himself immigrated from India to the United States while still a university student, writes that there are four signal factors that influence how a move to a foreign country will be emotionally experienced: first, whether the move is going to be temporary or permanent; second, the degree of choice one experienced in leaving one's country. Military dependent children, of course, typically have little choice in these decisions; third, the possibility of revisiting the home country. Those who can visit easily and frequently visit their country of origin suffer less than those barred from such "emotional refueling"; and fourth, the reasons for leaving one's home country.

The age at the time of the move to the foreign country is likewise an important variable as immigrant children at different ages will experience different acculturation problems. The situation with children who have had little voice in the immigration decision [as with many military dependents] can be especially difficult: "Parents may be voluntary or involuntary emigrants, but children are always 'exiled': "they are not the ones who decide to leave and they cannot decide to return at will" [41]. The period of adolescence, in particular, may possibly be even more difficult, where the youth is faced with the developmental task of a psychological "second individuation" [42].

\section{Discussion}

The U.S. military has become increasingly aware of the importance of taking care of the families of its service members [43]. Admiral Mike Mullen, Chairman of the Joint Chiefs speech, 2009, quoted in MacDermid Wadsworth and Southwell [44]. Military policy makers have now accepted that maintaining the overall integrity of the service member's family is integral to the member's wellbeing. There is also a recognition that mission success depends upon the wellbeing of these families. If a service member is overly distracted by concerns about their family then mission success can be compromised. Extending upon this military concern for dependents this paper has 
provided a brief scope review of the literature on the impact of military deployments upon children, as well as the impact upon them when confronted with a PCS to a foreign country. As noted, the literature on PCS for military children to foreign countries, in particular, is relatively sparse or non-existent, and in need of further development. The bridging literature of the impact upon immigrant children is more readily available but it is also merely a rough analog for our purposes. In clinical experience it is observed that numerous children are negatively impacted psychologically when they are confronted with the kind of unique double- stressor previously described; namely, having undergone the inherent stress of a PCS move to a foreign country, which is then subsequently followed by having a parent deploy to another geographical location. These deployments can sometimes be announced with little notice and their duration can be quite variable or even indeterminate. The level of risk for the deploying parent on any particular deployment can also vary and the details of the assignment may not be known to the family- this situation creates open space for the emergence of catastrophic thinking and a depression spiral. Though this kind of double-stressor is a relatively common experience among military children, and taken for granted as simply part of military family life, here is no research that has directly addressed this double-stressor phenomenon. This brief review is thus a tentative first step toward bridging this gap in our understanding.

Though this review has briefly referred to children from immigrant families as a rough bridging concept, it is recognized that the differences between the military child's experiences of settling into their host nation are also sharply distinct from that of children from an immigrant family. The military child typically knows that he or she will be in the host nation temporarily, usually for a matter of several years or more; they know they have not settled there permanently. Over time they will adapt to the host nation's culture and language in degrees, with some, as suggested by Berry, adapting better and more successfully than others. Yet to adapt successfully may not be as imperative for the military child as it would be for the immigrant child, who understands that the new country will become their permanent home. For both the immigrant child, as well as the military dependent child, if they are to successfully adapt to their new culture, they must each actively work to learn the language and customs of the new country and find a place for themselves within it. Yet the military child is not necessarily required to invest the same amount of emotional energy and active learning into the process of integrating into the host country because they have already accepted that their life within it is transitory. They know they will eventually be returning to their land of origin, their psychological "real home", as it were, when their tour of duty with their family is over. The military child will also recognize that the circumstances of their stay far exceed a mere vacation as a tourist; they are not merely passing through the host nation's cultural space and absorbing what they can from it. Rather, as they settle into their host nation, they will have entered into a prolonged transitional space. Thus, whilst within the host culture they are neither short term guests (as tourists), nor are they permanent residents, such as with the case of the immigrants who are intent on settling in to a new life.

For both the immigrant child as well as the military dependent child, their initial psychological task is to negotiate the tension arcs within this transitional culture space, psychologically balancing between the world they have left and the new one they have now entered. Typically these children are psychologically situated somewhere in the middle of the tension arc between these two cultural worlds. For some of these immigrant and military children who are more successful in the process, this oscillation between cultural worlds may begin to feel easier, almost second nature. For these children the process is comparable to the manner in which bilingual speakers eventually can fluidly transition between several languages. Some of these children begin to think of themselves as "bi-cultural." To positively transcend one's current cultural framework, and thereby expand one's cognitive mappings and beliefs about oneself and others in the world, can for some children feel liberating. As some of these successful adaptors begin to acclimate to their new culture and develop a more transcendent world view, they can effectively straddle the bridge between their previously held cultural views developed in their country of origin and their newfound assumptions about their core identity and host culture. This growth process also entails tolerating lengthy periods of ambiguity and uncertainty, and a deep sense of loss. Yet knowing that one is on the way to a larger, indeed, multicultural view of the world, will not be enough for some children to prevent breakthrough anxiety and mood disruption[or their behavioral equivalents] as well as a transient sense of identity confusion. For some military dependent children who negotiate this acculturation process less proficiently, their adaptation to the new culture may be fraught with acculturation stress and the emergence of emotional symptoms [45]. Maintaining a sense of continuity of one's identity can be challenged when moving from one country to another or from one culturally distinct region of the same country to another. This transition can mobilize a destabilization-re-stabilization process Vis-a'-Vis the internal psychic structure.

Among the children observed and treated in an overseas military clinic, most of their emotional deregulation and associated behavioral symptoms tend to be transient and reversible, and would be generally conceptualized within the realm of brief adjustment reactions. Behavioral health treatment typically focuses upon helping the child restore their internal sense of connection with the absent culture through the use of familiar symbolic connections such as heart-felt photographs of their home country and family, count-down calendars to measure when they will return home, special blankets (for younger children) and stylized clothing ( with 
national monograms or logos of sports teams), special family treats at food establishments that offer food reminiscent of home (i.e., pizza or hamburgers), and other symbolic objects and paraphernalia that evoke the internal emotional presence of the former culture. As noted by [46] and as operational zed in our clinic, "to maintain a sense of belonging and continuity, it is important to have exposure to familiar symbols: the dress, the language, the food, and the participation in rituals all reinforce a sense of identity (p. 144)."

As indicated earlier, when this ongoing and often somewhat psychologically destabilizing process of adapting to the host country is then disrupted by the departure of a parent for duty elsewhere [typically out of the country, for variable lengths of time and with variable degrees of risk], it can feel for some children like the proverbial "last straw." Especially for those children who have struggled less successfully with their adjustment to the host country, their excess load of accumulated cultural stress creates a weakened psychological foundation that ill prepares them for the sudden and unanticipated shock of their parent's deployment. The added distress now imposed upon the child by the parent's deployment may also be amplified and reinforced by the instability that reverberates throughout the family system with the parent's departure.

Parents left behind may feel overwhelmed with managing the household alone and when their previously relied upon social support systems may still be in the U.S. and no longer available. Under these conditions, the added emotional support that an emotionally fragile child needs may be unavailable or of sufficient measure to them at a time when they need it the most. At a fundamentally deeper level, what is at stake for children confronting this double-stressor is the temporary destabilization of their identity, as well as confrontation with yet more grief and loss not only for their dislocation from their native culture, but now also with the additional loss regarding the absent parent. The confluence of these two basic psychological processes (i.e., culture shock and parental departure) can deepen the child's sense of grief and loss and engender significant anxiety and emotional disequilibrium.

The psychosocial factors that can influence how successfully these military dependent children adjust to this kind of doublestressor would include: individual and developmental factors [child's stage of development], as well as individual temperament and personality characteristics, such as cognitive flexibility, creativity, intelligence, and curiosity. Those children who are affected most adversely by this double-stressor are also typically diagnosed as falling within an adjustment disorder spectrum. Symptoms typically have their onset after the child has received the news of the parent's future departure, though in some cases the emotional reaction may be delayed. Some of these children who might have been initially described as "struggling adapters" to the new culture may have been able to contain their distress at a relatively sub-clinical level until the news of the parental deployment. At that point, with he added weight of the parent's deployment; their symptom level can tip from the sub-clinical to the clinical level.

The range of presenting symptoms in the clinic can be wide despite the identified etiological common pathway to symptom expression. Among younger children an array of externalizing behaviors may emerge: regression with toileting behaviors is common, as well as changes in eating habits and food preferences, more disturbed sleep with breakthrough nightmares, increased conflict with siblings and peers, and more behavioral acting out at home or school (or pre-school).Younger children respond better to the use of evocative physical objects that have the potential to re-instill their felt emotional connection with the absent parent (i.e., "daddy dolls", special blankets and pillows, special pajamas, pictures of the absent parent, special bracelets and charms, etc.). With older latency age and adolescent children, there will be observed an admixture of both externalizing and internalizing behaviors. Among these children, for example, it is not uncommon to observe more social withdrawal and isolation (such as spending more time in their bedroom alone listening to music or playing video games), lower academic performance with grades and negative attitudes toward school, and more arguments with siblings and parents. Older children can be therapeutically re-directed to re-establish or create anew their support links with friends (or on-line communities), and with personally valued activities (i.e., sports, martial arts, creative arts projects, etc.). Both children and adolescents generally respond positively to behavioral health approaches that help them to internally evoke (or re-evoke) a temporarily disrupted emotional connection with the deployed parent [47] as well as with their disrupted sense of connection with their culture of origin [48-50].

\section{Conclusion}

This article is a brief scoping review that adds to our understanding of the complex and unique stressors facing the children of military service members with deployments. It is noted that there is a range of clinical reactions that can be observed after these children have already made their PCS to a foreign country and then a parent is subsequently called to a deployment [51]. This is a compounding phenomenon which at present is not yet fully understood. Children who have adopted to the host culture well may be more resilient and at less risk for emergent symptoms when confronted with a subsequent parental deployment. Such emotionally de-centering experiences, though typically transient and reversible are not uncommon among military children but to date they have not been clinically researched. Clinicians should be alert to the potential effects of this double-adjustment requirement for these children who are living abroad. These affected children do tend to respond adequately, in most cases, to brief behavioral health interventions that focus upon helping the child to internally restore a ruptured sense of continuity and connection with the 
absent parent during the deployment, as well as their longing to have restored their sense of connection with their absent culture in the United States. These cases are typically diagnosed as a variation of adjustment disorder. More psycho education and family readiness training may be indicated to help families prepare for and militate against this form of double-stressor phenomenon when it occurs. Clearly more research is needed in this area before more prescriptive and firmer conclusions can be drawn and strategic interventions for them can be developed $[52,53]$.

\section{Footnotes:}

a) Cited in Bartlett's Familiar Quotations (1992). John Bartlett, Justin Kaplan, (General Editor)-16th Edition. Little, Brown \& Company (Canada) Limited. (p. 10:1).

b) According to the APA Concise Dictionary of Psychology (2009) the term Resilience is defined as: "the process and outcome of successfully adapting to difficult or challenging life experiences, especially through mental, emotional, and behavioral flexibility and adjustment to external and internal demands. A number of factors contribute to how well people adapt to adversities, predominant among them (a) the ways in which individuals view and engage with the world, (b) the availability and quality of social resources, and (c) specific coping strategies. Psychological research demonstrates that resources and skills in each of these domains associated with more positive adaptation (i.e., greater resilience) can be cultivated and practiced" (p. 434).

\section{References}

1. Johnson SJ, Sherman MD, Hoffman JS, James LC, Johnson PL, et al (2007) Psychological needs of U.S. military service members and their families: A preliminary report. American Psychological Association. Washington DC, USA.

2. Park N (2011) Military Children and families: Strengths and challenges during peace and war. American Psychologist 66(1): 65-72.

3. MacDermid SM, Olson TM, Weiss H (2002) Supporting military families throughout deployment. Military Family Research Institute.

4. Pincus SH, House R, Christensen J, Adler LE (2005) The emotional cycle of deployment: a military family perspective.

5. Pincus SH, House R, Christensen, J, Adler LE (2001) The emotional cycle of deployment: A military family perspective. Journal of the Army Medical Department 615-623.

6. Wexler HK, McGrath E (1991) Family member stress reactions to military involvement separation. Psychotherapy 28(3): 515-519.

7. Frankel H, Snowden LR, Nelson LS (1992) Wives adjustment to military deployment: An empirical evaluation of a family stress model. International Journal of Sociology of the Family 22: 93-117.

8. Wood S, Scarville J, Gravino K (1995) Waiting wives: Separation and reunion among Army wives. Armed Forces \& Society 21: 217-236.

9. Rosen LN, Teitelbaum JM, Westhius D (1993) Stressors, stress mediators, and emotional well-being among spouses of soldiers deployed to the Persian Gulf during Operation Desert Shield/Storm. Journal of Applied Social Psychology 23(19): 1587-1593.
10. Hosek J, Kavanagh J, Miller L (2006) How Deployments Affect Service Members. The Rand Corporation, Santa Monica, California, USA.

11. MacDermid SM (2006) Multiple transitions of deployment and reunion for military families. Military family Research Institute.

12. Morris M (2006) Military families provide insight on adjusting to constant change. Purdue University News, Indiana.

13. Friedman S (2013) Research on the well-being of military children: Future directions.

14. Hammer LB, Cullen JC, Marchand GC, Dezsofi JA (2006) Reducing the negative impact of work family conflict on military personnel: Individual coping strategies and multilevel interventions. In CA Castro, AB Adler, TW Britt (Eds.), Military life: The psychology of serving in peace and combat. The military family pp. 220-242.

15. Patterson JM, Mc Cubbin HI (1984) Gender roles and coping. Journal of Marriage \& the Family, 46(1): 95-104.

16. Walsh F (2006) Strengthening family resilience ( $\left.2^{\text {nd }} E d n\right)$. The Guilford Press, New York, USA.

17. Weins TW, Boss $P$ (2006) Maintaining family resiliency before, during and after military separation. In CA Castro, AB Adler, CA Britt (Eds.), Military Life: The psychology of serving in peace and combat. Praeger Security International, Bridgeport, CT, USA, 1-4: pp. 13-38.

18. Jensen PS, Xenakis SN, Wolf P, Bain MW (1991) The military family syndrome revisited: By the numbers. Journal of Nervous and Mental Disease 179(2): 102-107.

19. Jensen PS, Watanabe HK, Richters JE, Cortes R, Roper M, et al (1995) Prevalence of mental disorder in military children and adolescents: Findings from a two-stage community survey. Journal of the American Academy of Child and Adolescent Psychiatry 34 (11): 1514-1524.

20. Fox NA, Henderson HA, Perez Edgar K, White LK (2008) Developmental cognitive neuroscience. In CA Nelson, M Luciana (Eds.), Handbook of developmental cognitive neuroscience ( $2^{\text {nd }}$ ed.), pp. 839-853.

21. Belsky J, Pluess M (2009) Beyond diathesis stress: Differential susceptibility to environmental influences. Psychological Bulletin 135: 885-908.

22. Lerner RM, Almerigi JB, Theokas C, Lerner JV (2005) Positive youth development A view of the issues. The Journal of Early Adolescence 25: $10-16$.

23. Lerner JV, Phelps E, Forman YE, Bowers EP (2009) Positive Youth Development Handbook of Adolescent Psychology.

24. Huisman S (2014) The Impact of PCS Moves on your Kids.

25. Drummet AR, Coleman M, Cable S (2003) Military families under stress: Implications for family life education. Family Relations 52(3): 279-287.

26. Ender MG (2000) Beyond adolescence: The experiences of adult children of military parents. In Martin JA, Rosen LN, Sparacino LR (Eds.), The Military Family A practice guide for human service providers. pp. 241-256.

27. Finkel LB, Kelley ML, Ashby J (2003) Geographic mobility family and maternal variables as related to the psychosocial adjustment of Military children. Military Medicine 168 (12): 1019-1024.

28. Segal MW (2006) Military family research. In Mangelsdorff AD (Edn.), Psychology in the Service of National Security. American Psychological Association, Washington DC, USA.

29. Watanabe HK, Jensen PS (2000) Young children's adaptation to a military lifestyle. In JA Martin, LN Rosen, LR Sparacino (Eds.), The Military Family: A practice guide for service providers. Praeger, Westport, Connecticut, USA. 
30. Amen DJ, Jellen L, Merves E, Lee RE (1988) Minimizing the impact of deployment separation on Military children: Stages current preventive efforts and system recommendations. Military Medicine 153: 441-446.

31. Murray JS (2002) Helping children cope with separation during war. Journal for Specialists in Pediatric Nursing 7(3): 127-130.

32. Stafford EM, Grady BA (2003) Military family support. Pediatric Annals 32(2): 110-115.

33. (2009) American Psychological Association Task Force on Working with Refugee Children and Families: Update for Mental Health Professionals The Psychosocial Effects of War on Children and Families Who are Refugees from Armed Conflict Residing in the United States.

34. Berry JW (2005) Acculturation: Living successfully in two cultures. International Journal of Intercultural Relations 29: 697-712.

35. Hartmann H (1959) Comments on the psychoanalytic theory of the ego. In Essays on Ego Psychology, International Universities Press, New York, USA, pp. 113-141.

36. Garza Guerrero AC (1974) Culture shock: its mourning and the vicissitudes of identity. J Am Psychoanal Assoc 22(2): 408-429.

37. Handlin $O$ (1973) The Uprooted: The Epic Story of the Great Migration that Made the American People. Boston MA, USA.

38. Ticho GR (1971) Cultural aspects of transference and counter transference. Bulletin of the Menninger Clinic 35(5): 313-326.

39. Akhtar S, Jason Aranson (1999) Immigration and Identity Turmoil Treatment and Transformation. New Jersey, USA.

40. Volkan VD (1999) Nostalgia as a linking phenomenon. Journal of Applied Psychoanalytic Studies, 1(2): 169-179.

41. Grinberg L, Grinberg R (1989) Psychoanalytic Perspectives on Migration and Exile. New Haven, USA.

42. Blos P (1967) The second individuation process of adolescence. Psychoanal Study Child 22: 162-186.
43. Heilmann SG, Bell JE, McDonald GK (2009) Work-home conflict: A study of the effects of role conflict on military officer turnover intention. Journal of Leadership \& Organizational Studies 16(1): 85-96.

44. Macdermid Wadsworth S, Southwell K (2011) Military families: Extreme work and extreme "work-family." The Annals of the American Academy of Political and Social Science 638(1): 163-183.

45. Ramanajum BK (1997) The process of acculturation among AsianIndian immigrants. In PH Elovitz, C Kahn (Eds.), Immigrant Experiences: Personal Narrative and Psychological Analysis. Associated University Presses, Cranbury, New Jersey, USA, pp. 139-147.

46. Piaget J (1937) The Construction of Reality in the Child. Basic Books, New York, USA.

47. Burgner M,Edgcumbe R(1972) Some problems in the conceptualization of early object relations. Psychoanalytic Study of the Child 27: 315-333.

48. (2007) The Psychological Needs of US Military Service Members and their Families: a Preliminary Report.

49. (2009) APA concise dictionary of psychology American Psychological Association. USA.

50. (2011) CNA Workshop on the Scientific Study of Military Children.

51. National Military Family Association (2005) Report on the Cycles of Deployment: An Analysis of Survey Responses from April through September.

52. US Department of Defense (2010) The impact of deployment of members of the armed forces on their dependent children. Report to the Senate and House Committees on Armed Services Pursuant to National Defense Authorization Act for Fiscal year 2010 Section 571.

53. Wright KM, Burrell LM, Schroeder ED, Thomas JL (2005) Military spouses: Coping with the fear and reality of service member injury and death. In CA Castro, AB Adler, CA Britt (Eds.), Military Life: The psychology of serving in peace and combat. Praeger Security International, Bridgeport, Connecticut, USA, 1-4.

\section{Your next submission with Juniper Publishers will reach you the below assets}

- Quality Editorial service

- Swift Peer Review

- Reprints availability

- E-prints Service

- Manuscript Podcast for convenient understanding

- Global attainment for your research

- Manuscript accessibility in different formats

( Pdf, E-pub, Full Text, Audio)

- Unceasing customer service

Track the below URL for one-step submission https://juniperpublishers.com/online-submission.php 